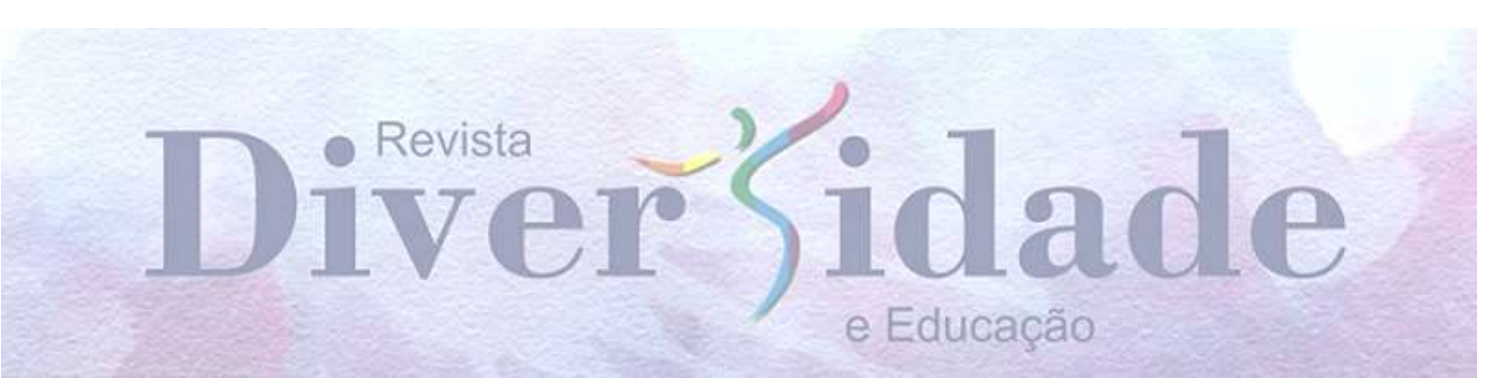

\title{
CONSTRUÇÃO DE PRINCESAS EM FILMES DE ANIMAÇÃO DA DISNEY
}

\author{
BUILDING PRINCESSES IN DISNEY ANIMATED FILMS
}

\section{CONSTRUYENDO PRINCESAS EN LAS PELÍCULAS DE ANIMACIÓN DE DISNEY}

\author{
Tânia Regina Zimmermann ${ }^{1}$ \\ Aline Alves Machado ${ }^{2}$
}

\section{RESUMO}

Este artigo analisa filmes animados da Disney enquanto fontes de pesquisa, nos quais o objeto são doze princesas (enquanto personagens protagonistas e simbólicas dos femininos). Considerando-se que os filmes animados são eivados de representações histórico-culturais, o recorte temporal é de 1937 a 2016, abarcando filmes que compõem a franquia 'Disney Princesa', por meio de uma pesquisa qualitativa através da metodologia de revisão bibliográfica e análise do discurso sob a perspectiva das relações de gênero. Conclui-se que essas produções cinematográficas englobam um poder formativo e representativo da sociedade, no entanto, ainda com marcas patriarcais e machistas, de valorização à beleza dos corpos e ao casamento heteronormativo. Outrossim, alguns roteiros apresentam um discurso feminista sutil, com pautas ligadas ao empoderamento feminino, à diversidade, à representatividade, ao gênero e aos questionamentos interseccionais, abrindo caminhos para uma formação midiática e educacional mais justa, plural e equânime.

PALAVRAS-CHAVE: Filme de animação. Gênero. Feminismo.

\section{RESUMEN}

Este artículo analiza las películas de animación de Disney como fuentes de investigación, en las que el objeto son doce princesas (como protagonistas y personajes simbólicos de las mujeres). Considerando que las películas animadas están repletas de representaciones históricas y culturales, el período de tiempo es de 1937 a 2016, abarcando películas que integran la franquicia 'Disney Princess', mediante una investigación cualitativa a través

\footnotetext{
${ }^{1}$ Doutora em História Cultural pela Universidade Federal de Santa Catarina e professora da graduação e pós-graduação da Universidade Estadual do Mato Grosso do Sul, Brasil.

${ }^{2}$ Mestranda do Programa de Pós-Graduação em Educação PGEDU/UEMS e bolsista do PIBAP/UEMS, Paranaíba, Mato Grosso do Sul, Brasil.
} 
de la metodología de revisión bibliográfica y análisis de la discurso desde la perspectiva de las relaciones de género. Se concluye que estas producciones cinematográficas encierran un poder formativo y representativo de la sociedad, sin embargo, aún con marcas patriarcales y sexistas, valorando la belleza de los cuerpos y el matrimonio heteronormativo. Además, algunos guiones presentan un discurso feminista sutil, con pautas vinculadas al empoderamiento femenino, la diversidad, la representatividad, el género y las cuestiones interseccionales, abriendo caminos para una formación mediática y educativa más justa, plural y equitativa.

PALABRAS-CLAVE: Película animada. Género. Feminismo.

\section{ABSTRACT}

This article analyzes Disney animated films as documentary sources of research, in which the object is twelve princesses (as protagonists and symbolic characters of women). Considering that animated films are filled with historical and cultural representations, the timeframe is from 1937 to 2016, covering films that make up the 'Disney Princess' franchise, through a qualitative research through the methodology of bibliographical review and discourse analysis from the perspective of gender relations. It is concluded that these cinematographic productions include a formative and representative power of society, however, still with patriarchal and sexist marks, valuing the beauty of bodies and heteronormative marriage. Furthermore, some scripts present a subtle feminist discourse, with guidelines linked to female empowerment, diversity, representativeness, gender and intersectional questions, paving the way for a fairer, plural and equitable media and educational formation.

KEYWORDS: Animated film. Genre. Feminism.

$$
* * *
$$

\section{Introdução}

Conhecido como a sétima arte, o cinema é uma das manifestações culturais humanas. Desde o seu surgimento em fins do século XIX, esse recurso midiático de registro e exibição de imagens em movimento, que são projetadas em uma tela, encanta o público e as gerações. É a arte de representar até os mais obscuros sentimentos, desejos e necessidades humanas. O cinema é uma produção cultural da sociedade e representa um poderoso instrumento de influência individual e coletiva. Historicamente, estudar cinema é compreender como o/a homem/mulher [...] "se vê e representa a si mesmo e de que forma recria em imagens o seu mundo [...]" (MEIRELLES, 1997, p. 114). Desse modo, as produções cinematográficas contemplam representações, que podem ser perscrutadas tanto como potencial documento histórico de pesquisa, quanto como um importante instrumento didático de contextualização histórica e de formação humana.

O historiador francês Marc Ferro foi um dos pioneiros no trabalho de compreender o cinema enquanto agente e fonte da história (LE GOFF, 1990). Em seus estudo, Marc 
Ferro observou que "[...] desde que o cinema se tornou uma arte, seus pioneiros passaram a intervir na história com filmes, documentários ou de ficção, que, desde sua origem, sob a aparência de representação, doutrinam e glorificam [...]" (FERRO, 1992, p.13). Assim, enquanto produções culturais, os filmes são uma rica fonte de pesquisa e um precioso recurso para análise do discurso de gênero e das relações de poder na sociedade, pois sugerem comportamentos e identidades sociais de regulação das vidas humanas, além de representar subjetividades (RABELO, 2016).

Considerando que imaginário "é constituído e se expressa por ideologias e utopias [...] por símbolos, alegorias, rituais, mitos" (CARVALHO, 1987, p. 11), e visto que a produção de um filme é fruto de um trabalho coletivo, que envolve o imaginário de uma multiplicidade de pessoas e/ou equipes (autor/a, diretor/a, atores/atrizes, além de equipes de som, luz, imagem, figurino, etc.), o cinema é um rico campo de pesquisa, repleto de possibilidades, na qual o/a historiador/a pode resgatar ações de diferentes de grupos humanos e em diferentes dimensões sociais. Ainda, a mensagem, própria do roteiro, também é digna de análise e observação, pois tanto democratiza o conhecimento, quanto difunde padrões, ideologias e culturas por todos os cantos do planeta. Nesse sentido,

[...] voltado para o consumo de massa e necessitando de grande investimento de capitais o cinema foi rapidamente apropriado pelo sistema capitalista, transformando-se em rendosa fonte de lucros. Desse modo pode-se prever as pressões sociais e econômicas que envolvem a realização de um filme [...] (MEIRELLES, 1997, p. 116).

Assim como o conhecimento é poder, os filmes como cultura de massa, também são disseminadores de pontos de vista políticos, históricos, entre outros. Nenhum filme é neutro, mas sim produto do contexto em que foi editado e produzido. Nessa conjuntura, também podemos incluir os filmes animados. Do mesmo modo, essa categoria de filmes vai muito além de singelos desenhos de entretenimento ao público infanto-juvenil e/ou adjacentes. O cinema de animação, sem dúvidas, detém um poder formativo e representativo, e deste modo, a análise de suas relações discursivas apresenta uma infinidade de possibilidades aos/às pesquisadores/as e aos/às professores/as:

[...] tornar visíveis as relações entre poder e conhecimento e, ao mesmo tempo, questionar aquilo que é, com frequência, tomado como natural, os/as professores/as e os/as críticos podem usar os filmes animados da Disney pedagogicamente para que os/as estudantes e outras pessoas possam ler esses filmes dentro, contra e fora dos códigos dominantes em que eles se baseiam [...] (GIROUX, 1995, p. 64). 
Diante do exposto, o presente artigo "Construção de princesas em filmes de animação da Walt Disney", é parte de uma pesquisa qualitativa em desenvolvimento, que está sendo realizada a partir da metodologia de revisão bibliográfica e estudo de filmes, associada aos procedimentos da análise do discurso, assim como, a articulação entre história, cinema e teorias feministas. Nesse ínterim, o objetivo é analisar discursos de gênero em filmes animados da Walt Disney enquanto fontes de estudo, destacando a princesa como objeto de estudo, e ainda, compreendendo-a como personagem protagonista, histórico-cultural e simbólica do feminino. O recorte temporal é de 1937 a 2016 e o corpus documental por doze filmes: Branca de Neve e os Sete Anões (1937), Cinderela (1950), Bela Adormecida (1959), A Pequena Sereia (1989), A Bela e a Fera (1991), Aladdin (1992), Pocahontas (1995), Mulan (1998), A Princesa e o Sapo (2009), Enrolados (2010), Valente (2012) e Moana (2016). Considerando especificamente os filmes de animação de princesas da produtora cinematográfica Walt Disney, que são produzidos para divertirem e entreterem especialmente o público infanto-juvenil, a partir de referenciais teóricos indaga-se: quais discursos de gênero os filmes de animação disseminam?

A fundamentação teórica para análise discursiva dos filmes animados que compõem o corpus documental desta pesquisa foi feita a partir de uma revisão bibliográfica dos trabalhos de Simone de Beauvoir, Joan Scott, Judith Butler, Guacira Lopes Louro, Michelle Perrot e Tereza de Lauretis. Para compreender as construções discursivas dos filmes e as representações que estes produzem, paralelamente, associamos as produções cinematográficas a algumas perspectivas da análise de discurso de Michel Foucault (1996). Entendemos o discurso não somente como a palavra enquanto enunciado verbal ou escrito, mas na forma manifesta de desejo e, também, objeto de desejo. Nesse sentido, os acontecimentos discursivos são aqui estudados a partir dos filmes de animação eleitos, como práticas que repercutem no imaginário social em confluências.

Nessa abordagem ainda nos valemos de apontamentos de Céli Pinto (2005), pois ela entende que o discurso nos atravessamentos de diferentes esferas da vida necessita de uma compreensão na perspectiva dos sentidos, das significações. Pinto reitera que esse processo de análise discursiva não deve ser circunscrito só a fonte, mas na amplitude de discursos em disputa que significam essa pesquisa dentro e fora das produções fílmicas, pois “[...] o corpo discursivo deve ter uma unidade que possibilite estudá-lo como um 
fenômeno específico e conter nessa unidade a pluralidade de discursos que possibilite dar conta de hipótese de trabalho" (PINTO, 2005, p. 95).

Nessas disputas discursivas apontamos para o reforço de parte dessas produções fílmicas em determinar identidades ligadas ao que é ser mulher e feminina, mas que não são fixas. No entanto, há um sentido reivindicado nos discursos que se pauta em fixar marcações próprias naquele cenário em disputa. Essa questão, Pinto entende como tentativas de discurso de fixar sentidos dentro da formação discursiva (PINTO, 2005, p. 94).

Com base nessa perspectiva do discurso, enquanto instrumento de ordenamento do mundo em disputa e construído historicamente, é possível perceber que, ao longo da história, relações de poder e de dominação se inter-relacionam com as produções culturais da sociedade, buscando criar papeis diferenciados e/ou hierarquizados entre homens e mulheres. Assim, o discurso enquanto prática social, por meio de construções históricas, vai validando as inúmeras formas de ser e de agir do sujeito, produzindo as subjetividades (FOUCAULT, 1969; 1994). Assim, os gêneros são culturalmente construídos, alicerçados nas intrínsecas relações de poder, produzindo subjetividades acerca de como ser criança e ser mulher (SCOTT, 1995). Desde a infância, a menina vai aprendendo a ser passiva e submissa - por meio de canções, textos literários e outros recursos ou mídias. Em relação aos filmes animados de princesas, esses remetem ao recato, ao culto à beleza e às atividades domésticas que reforçam desigualdade, preconceitos e até violências de gênero.

A partir da célebre frase de Simone de Beauvoir “[...] ninguém nasce mulher; tornase mulher [...]" (BEAUVOIR, 2009, p. 265), associada ao conceito de Judith Butler de que

[...] se o caráter imutável do sexo é contestável, talvez o próprio construto chamado 'sexo' seja tão culturalmente construído quanto o gênero; a rigor, talvez o sexo sempre tenha sido o gênero, de tal forma que a distinção entre sexo e gênero se revela absolutamente nenhuma [...] (BUTLER, 2003, p. 25).

Então podemos considerar que tanto o sexo como o gênero são historicamente construídos, de modo que não há determinismo biológico (macho/fêmea) ou de gênero (feminino/masculino), pois são conceitos culturalmente construídos. Assim, "as escritoras Joan Scott e Judith Butler, inspiradas nas obras do filósofo Michel Foucault e seu entendimento do discurso, se desdobraram a partir do legado de Simone de Beauvoir 
e dos problemas do "tornar-se mulher'” (MENDES, 2000, p. 21). Neste sentido, o termo 'gênero' surge com o objetivo de dar vozes às mulheres enquanto sujeitos sociais, anteriormente silenciadas ao longo da história. Para Scott (1995), gênero é uma validade acadêmica que pode ser entendida como uma categoria de análise histórica e construção social.

A partir das análises discursivas de gênero é possível desmistificar a ideia de que há características essencialmente femininas (como compaixão, passividade, acolhimento, fragilidade) e características essencialmente masculinas (como racionalidade, inteligência e força). Desmistificar o conceito de gênero significa ampliar as possibilidades das mulheres para que possam se comportar da maneira que quiserem. Assim, a princesa dos filmes animados, que antes era indefesa, passiva e submissa perdeu espaço para uma protagonista mais heroica, determinada e ativa, que luta por seus sonhos e ideais (KESTERING, 2017). Agora, a heroína se destaca por sua personalidade ativa e suas conquistas, e essas histórias de mulheres fortes, foram sendo incorporadas pela produtora cinematográfica Walt Disney como uma nova e atualizada vertente de princesas.

Também é importante registrar que essas transformações físicas e de personalidade que as princesas do cinema de animação Disney vêm passando são reflexos de lutas feministas pela ruptura dos padrões patriarcais socialmente construídos. Além disso, uma das preocupações do movimento feminista é compreender como a mulher é representada no cinema, assim como, seus estereótipos e imaginários coletivos. Desse modo, a crítica feminista revela que a mulher é representada como um objeto de desejo e/ou repulsa: prostitutas ou santas, amantes ou traídas, donas de casa ou profissionais, sexy ou masculinizadas, entre outros. Neste contexto e em contraposição ao machismo cinematográfico, surgiu a Teoria Feminista do Cinema. Dentre as teóricas que se debruçam sobre a temática, destacamos Tereza de Lauretis, a qual revela que "[...] o gênero como representação e auto representação é produto de diferentes tecnologias sociais, como o cinema [...]" (DE LAURETIS, 1994, p. 208). Segundo de Lauretis, o cinema é uma tecnologia de criação de subjetividades e de representações de gênero.

Portanto, o feminismo surgiu com a propósito de desnaturalizar a ideia patriarcal de mulher como 'sexo frágil', digna dos afazeres domésticos e propriedade do homem, a quem deveria servi-lo. Enquanto movimento histórico-cultural, social, político e filosófico traz a ideia de equivalência de direitos entre os sexos e igualdade de gênero, e como consequência, o empoderamento feminino. Por sua vez, o empoderamento 
feminino torna-se possível a partir da ampliação da participação das mulheres nos debates públicos e na tomada de decisões pessoais, profissionais, político-sociais, ou seja, é a emancipação da mulher em todos os assuntos. Atualmente, o movimento feminista apresenta uma pauta mais ampla e abrangente, aproximando suas pautas dos movimentos negros, dos movimentos de minorias, dos movimentos identidade de gênero e também, reivindica o reconhecimento da interseccionalidade das opressões (gênero, classe e raça, assim como, colonialidade e meio ambiente) (COLLINS, 2015; HOOKS, 1984; LUGONES, 2011). Em face a tudo isso, será analisado o processo de construção das princesas Disney.

\section{Adentrando ao universo das princesas Disney}

Os grandes idealizadores na construção do imaginário 'Disney'3 - como a empresa é popularmente conhecida - foram os irmãos Walter Elias Disney (1901-1966) e Roy Oliver (1893-1971). Atualmente é uma multinacional estadunidense, que trabalha com mídia de massa, sediada no Walt Disney Studios, que é um dos maiores e mais conhecidos estúdios de Hollywood. A Disney é um verdadeiro império do mundo cinematográfico, reconhecida mundialmente pelo pioneirismo na indústria de longas-metragens de animação e uma história de produção de filmes com ampla circulação e popularização.

No que tange aos filmes das princesas Disney caracterizam-se por representarem um padrão de beleza feminino e um enredo cuja problematização finda com um casamento heterossexual, como um símbolo da felicidade plena. Ainda, contextualizando Ballestrin (2017), é possível observar transformações históricas sob a influência dos movimentos pós-coloniais. Deste modo, as princesas dos filmes animados, passaram a substituir o estereótipo de trilogia inicial de princesas (Branca de Neve, Cinderela e Aurora), pois essas representavam a mulher 'bela, recatada e do lar', 'loira e de olhos claros' ou 'aquela branca como a neve'. Entretanto, nota-se que com os filmes de princesas lançados após a década de 90, a diversidade passa a ser introduzida no universo Disney, e a franquia passa a abarcar outras representatividades, subjetividades e até mesmo a interseccionalidade de raça, classe e gênero.

Deste modo, vale esclarecer que, ao longo dos anos, a Companhia Walt Disney, vem implantando, em suas produções cinematográficas, a diversidade de origens, etnias,

\footnotetext{
${ }^{3}$ A Companhia Walt Disney ou "The Walt Disney Company” foi fundada em 16 de outubro de 1923 em
} Los Angeles (EUA). 
culturas, estilos de vidas e até as conquistas pessoais das protagonistas como requisitos dignos de destaque para que a personagem seja respeitada e entendida como uma 'verdadeira princesa'4 . Seguindo essa mesma linha de raciocínio, as personagens femininas a serem estudadas nos filmes selecionados neste artigo são denominadas 'princesas', por comporem a franquia "Disney Princesa" ou “Disney Princess" ”, , e não necessariamente por suas origens em reinados ou castelos. Ainda, convém esclarecer que os filmes animados de princesas da Disney são geralmente produtos de adaptações dos contos de fadas, mas também, há filmes que são releituras de outras histórias conhecidas, ou ainda, roteiros de personagens inéditos.

FIGURA 1: Princesas da Disney ${ }^{6}$.

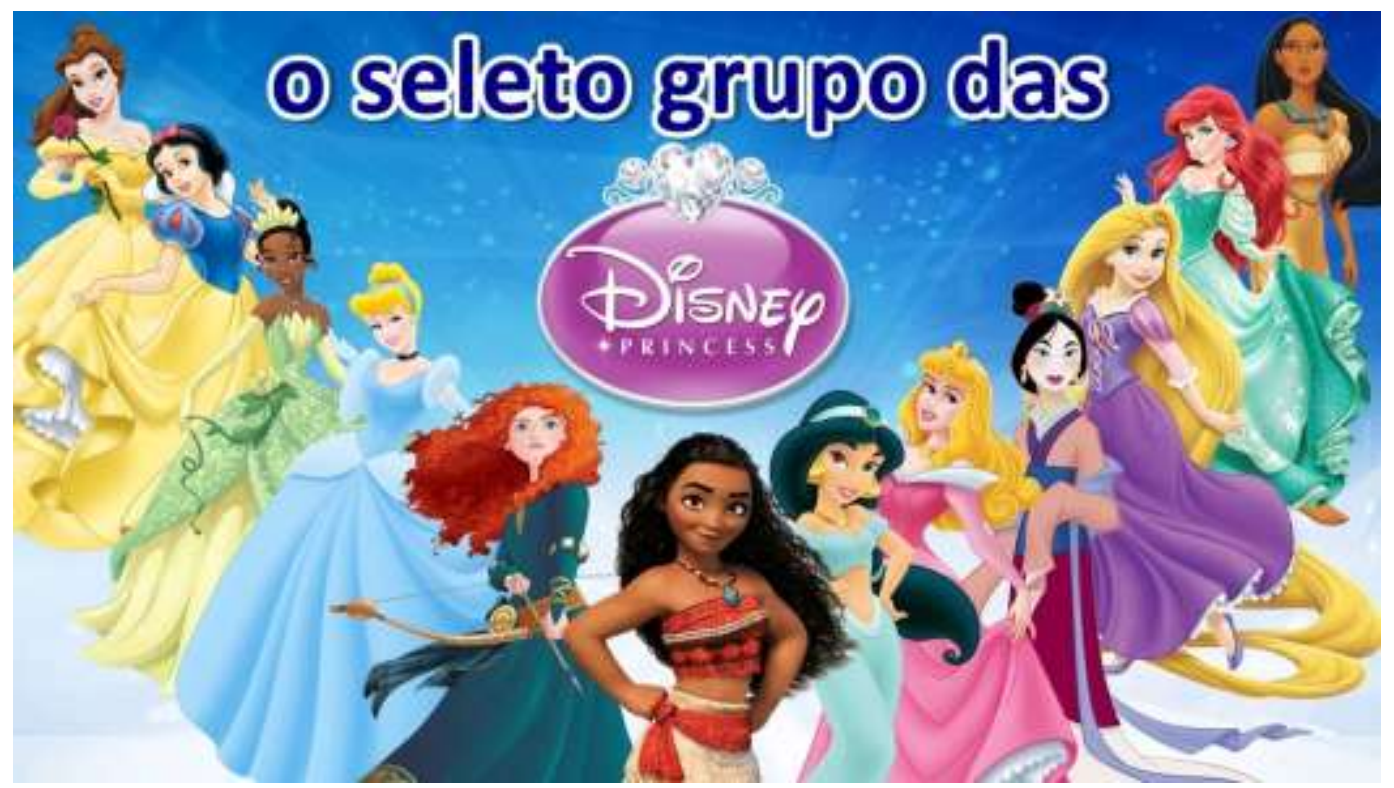

Fonte: https://i.ytimg.com/vi/O9y63GLDuqo/hqdefault.jpg. Acesso em: 01 set. 2020.

$\mathrm{Na}$ figura 1, estão destacadas as doze princesas que compõem o seleto grupo das "Princesas Disney", sendo fruto dos filmes de animação da Walt Disney, cujos respectivos nomes (da esquerda para direita) são: Bela, Branca de Neve, Tiana, Cinderela, Merida, Moana, Jasmine, Aurora, Mulan, Rapunzel, Ariel e Pocahontas. Pode-se notar,

\footnotetext{
${ }^{4}$ Requisitos para a coroação de uma personagem como "verdadeira princesa da franquia Disney Princesa": ser a protagonista em um filme animado (ou sequência de filmes) produzido pela Walt Disney; ser membro da realeza (seja por nascimento ou casamento), ser humana (ou metade humana, como Ariel); realizar um ato de heroísmo (no caso de Mulan) e ter sido sucesso de bilheteria e rentabilidade para a companhia (com exceção de Elza e Anna, que compõem a própria franquia Frozen).

${ }^{5}$ A franquia "Disney Princesa" ou "Disney Princess", que é uma marca mercadológica que investe em produtos relativos às princesas fílmicas e personagens correlatos, dirigidos ao público feminino, tais como brinquedos, vestuários, acessórios, materiais escolares e outros artefatos.

${ }^{6}$ A figura 1, cujo ilustrador é desconhecido, é capa do vídeo "Princesas Disney: Quem entra e quem sai?". Disponível em: https://www.youtube.com/watch?v=O9y63GLDuqo. Acesso em: 01 set. 2020.
} 
que geralmente os filmes de princesas são nomeados com o mesmo nome da protagonista, sendo exceções: A Bela Adormecida (da princesa Aurora), A Pequena Sereia (da princesa Ariel), Aladdin (da princesa Jasmine), A princesa e o Sapo (da princesa Tiana), Enrolados (da princesa Rapunzel) e Valente (da princesa Merida). Nessa figura, é possível analisar que, em linhas gerais, as princesas apresentam características majoritárias, tais como: vestido longo (com cintura marcada e saia rodada), cabelo longo (bem penteado, solto e liso), corpo longíneo (estrutura física magra e alta), cor branca (pele clara e traços finos tipicamente europeus) e postura ereta (com sorriso nos lábios e um toque de meiguice). Importante ressaltar que também há exceções quanto às características apresentadas, como por exemplo, a princesa central de destaque é Moana, que apresenta vestuário tipicamente indígena, pele bronzeada, estrutura corporal mais robusta, nariz largo e cabelos ondulados, ou seja, é uma antiprincesa contemporânea.

Portanto, a partir do referido corpus documental, referente ao período de 19372016, segue análise dessas protagonistas do cinema de animação da produtora Walt Disney, à luz estudos feministas, das relações de gênero e suas interseccionalidades.

\section{Análise do gênero feminino nos filmes animados}

A primeira produção cinematográfica da produtora "The Walt Disney" foi Branca de Neve e os Sete Anões ${ }^{7}$ (1937). O filme foi um sucesso de bilheteria $^{8}$, ganhador de várias premiações, digno de relançamentos e tornou-se um dos maiores clássicos do cinema de animação até os dias atuais:

[...] o êxito de Branca de Neve foi tamanho que se torna irrelevante enumerar seus prêmios e conquistas de mercado. Com Disney, a animação chegara ao seu amadurecimento artístico, definira-se como uma "arte separada dentro de outra arte". A animação, finalmente, emergia como forma válida de expressão artística e fazia ver todo seu poder como entretenimento [...]. (LUCENA JUNIOR, 2011, p. 119).

Enquanto primeira princesa representava o ideal de mulher burguesa da década de 1930, ou seja, exímia “[...] dona de casa, mãe, esposa obediente e sem qualquer desejo de

${ }^{7}$ O filme é a versão adaptada da Disney do contos de fadas "Branca de Neve", escrito pelos alemães de Jacob e Wilhelm Grimm.

${ }^{8}$ De acordo com a Wikipedia, o filme arrecadou 8 milhões de dólares em bilheterias ao redor do mundo. Disponível em: https://pt.wikipedia.org/wiki/Branca_de_Neve_e_os_Sete_An\%C3\%B5es_(filme). Acesso em: 03 set. 2020. 
ingressar no mercado de trabalho [...]" (QUEIROZ et al., 2016, p. 5), visto que como 'uma mulher de valor', ao adentrar na casa dos sete anões, demonstrou um desejo irrefutável de fazer uma faxina e organizar todo o ambiente desconhecido, já que representava as mulheres “[...] machucadas, passivas, feridas, ajoelhadas, humilhadas [...]” (BEAUVOIR, 2009, p. 284), que resignadas aguardavam silenciosamente e passivamente pelo príncipe salvador. O grande sonho de Branca de Neve era encontrar seu verdadeiro amor, o que ocorreu quando a princesa indefesa foi dada como morta e colocada em um esquife de vidro, porém foi salva com um beijo apaixonado do príncipe encantado, com o qual se casa. E assim finda-se a magia dos contos de fadas projetada em telas nas salas de cinema.

Nessa conjuntura, o século XX também pode ser chamado de 'século das mulheres' em virtude “[...] em razão das transformações aceleradas que propiciou à experiência feminina. Foi uma época de ampliação de direitos e oportunidades e de mudanças, tanto na qualidade de vida das mulheres, quanto no imaginário coletivo [...]" (PINSKY; PEDRO, 2013, p. 7). Após o lançamento de Branca de Neve e os Sete Anões, veio a Segunda Grande Guerra (1939-1945), que trouxe alterações em toda sociedade, dentre as quais ressaltamos: “[...] introdução das mulheres no meio fabril, enquanto homens iam para frente de batalha nas trincheiras [...]" (TARDIN; BARBOSA; LEAL, 2015, p. 11), e ainda "[...] campanhas publicitárias governamentais eram realizadas a fim de impulsionar a ida feminina para as fábricas [...]" (TARDIN; BARBOSA; LEAL, 2015, p. 11), tais como a famosa campanha estadunidense “We can do it!"”. Entretanto, pós-guerra, todos/as deveriam reassumir seus 'lugares de direito' preconizados pela sociedade patriarcal: os homens retornem às fábricas (e demais espaços públicos) e as mulheres voltarem ao ambiente privado e reassumirem os trabalhos domésticos, pois essa era ordem 'natural' a ser cumprida (TARDIN; BARBOSA; LEAL, 2015). Em consonância, era necessário que o cinema estruturasse estratégias para conter o avanço dos ideais feministas:

[...] num tempo de pós-guerra, parecia necessário, de algum modo, deter ou reverter o avanço feminino que fora possibilitado pelo longo conflito. O cinema ajudaria a promover a "volta ao lar" e a recomposição da estrutura familiar tradicional. Roteiros de inúmeras comédias, romances ou dramas passavam a tratar daquele que se

\footnotetext{
9 A imagem "We Can Do It!", de J. Howard Miller, foi criada para a fábrica Westinghouse Electric Corporation, em 1943, com o objetivo de incentivar as mulheres americanas a trabalharem nas fábricas, durante a Segunda Guerra Mundial. Posteriormente, foi incorporada pelo movimento feminista, trazendo a ideia de que "Sim, nós mulheres podemos fazer isso!" como símbolo da desconstrução de ideias machistas, papeis de gênero e conceito de mulher como sexo frágil.
} 
colocava como o novo dilema feminino: a escolha entre a família (casamento e filhos) ou a carreira profissional. Um happy end recompensava as mulheres que escolhiam certo, isto é, o lar, enquanto que as outras, muitas vezes representadas como "masculinizadas", duras e amargas, terminavam sós e infelizes [...] (LOURO, 2008, p. 83).

Em vista disso, no pós-guerra da década de 50, os estúdios Disney voltaram a investir em longas metragens e equipes de animação. Nesta época, houve o lançamento dos filmes Cinderela ${ }^{10}$ (1950) e A Bela Adormecida ${ }^{11}$ (1959), que consagraram as produções animadas estadunidenses. Neles, as princesas Cinderela e Aurora são representadas por jovens loiras, de olhos claros, corpo esguio e longilíneo. O príncipe é o salvador dessas princesas indefesas: seja no caso de Cinderela que é salva das explorações, violências e humilhações causadas pela madrasta e suas filhas maldosas; ou ainda, o salvamento do sono eterno a que Bela Adormecida estava destinada em virtude de um feitiço da bruxa. Dessarte, a beleza das princesas Branca de Neve, Cinderela e Bela Adormecida é motivo de conflito e rivalidades com outras mulheres. Vale salientar que nesses três primeiros filmes das princesas Disney:

[...] a beleza se tornaria um tema de grande importância, a busca pela feminilidade não estava exclusivamente na moda, como também na beleza. O clima era de sofisticação e a euforia ao buscar os cuidar da aparência. A mulher dos anos 1950 se tornou mais feminina, sofisticada e glamorosa, sendo representada pelas princesas loiras da Disney; Aurora e Cinderela, desde o estilo natural e jovial de Aurora, ao estilo sensual e fatal em Cinderela, quando ao se produzir e ir ao baile, ressalta a sua beleza, no longo vestido azul, sapato de cristal e penteado nobre (coque) [...] (QUEIROZ et al., 2016, p. 6).

Assim, essa trilogia inicial das princesas clássicas (AGUIAR; BARROS, 2015) representou o estereótipo da mulher-princesa difundido pelos estúdios Disney por longos anos: belas, jovens, exímias donas de casa, de perfil passivo e que sonham em encontrar a felicidade completa com o amor de um príncipe encantado. Sobre esse perfil de meninaprincesa, Simone de Beauvoir (2009) abarca:

[...] Ela aprende que para ser feliz é preciso ser amada; para ser amada é preciso aguardar o amor. A mulher é a Bela Adormecida no bosque, Cinderela, Branca de Neve, a que recebe e suporta. Nas canções, nos

${ }^{10}$ O filme é a versão adaptada da Disney do contos de fadas "Cinderela", escrito pelos alemães de Jacob e Wilhelm Grimm.

${ }^{11}$ O filme é a versão adaptada da Disney do contos de fadas "A Bela Adormecida", escrito pelos alemães de Jacob e Wilhelm Grimm. 
contos, vê-se o jovem partir aventurosamente em busca da mulher; ele mata dragões, luta contra gigantes; ela acha-se encerrada em uma torre, um palácio, um jardim, uma caverna, acorrentada a um rochedo, cativa, adormecida: ela espera. 'Um dia meu príncipe virá...' [...] (BEAUVOIR, 2009, p. 284)

Esse perfil de mulher proposto pelas princesas clássicas da Disney tem continuidade no decorrer do tempo: “[...] A espera do príncipe encantado é marcante nos anos 50, mas atravessa também outras décadas [...] As atitudes que a mulher deveria cultivar eram de passividade, ternura, afetividade, mas com uma pitada de sensualidade [...]" (XAVIER FILHA, 2009, p. 83). A té que em fins de 1980, surge com o filme Ariel ${ }^{12}$ (1989), a história da princesa-sereia que faz um acordo indevido com a bruxa do mar e aceita entregar sua voz à ela, em troca de tornar-se humana e conquistar o coração do príncipe Erick, com o argumento de que "o homem abomina tagarelas; garota caladinha ele adora; se a mulher ficar falando o dia inteiro e fofocando, o homem se zanga, diz adeus e vai embora!" (A Pequena Sereia, 1989). Desse modo, o diálogo musicado evidencia que Ariel, ainda traz como ideal uma mulher quieta, recatada, e acrítica, reforçando a ideia de que a mulher deve silenciar seus desejos e vontades, assim como, fazer o possível (ou impossível) para conseguir conquistar o amor de um homem. Em outras palavras, esse discurso fílmico evidencia a violência simbólica contra a mulher, o machismo e a crueldade do sistema patriarcal e revela que apesar de Ariel inicialmente lutar contra o sistema patriarcal, vacilou e acabou caindo nas ciladas do próprio sistema vigente, ou seja, simbolicamente, Ariel aceitou entregar sua voz ativa, aceitando a submissão e a desigualdade de gênero. Deste modo, essa cena revela que "[...] para a sociedade, a mulher só não é uma intrusa se tiver atitudes de submissão ao discurso dominante patriarcal; se a mulher reagir, poderá ser vítima de violência a qual se baseia na desigualdade de gênero construída culturalmente [...]" (GARCIA; SOUSA, 2015, p. 1000).

$\mathrm{Na}$ década de 90, são observadas as primeiras mudanças no estereótipo das princesas Disney a partir do lançamento dos filmes Bela (1991), Aladdin (1992), Pocahontas (1995) e Mulan (1998), de modo que se abre espaço para outras representatividades e para a diversidade ética, pois além das princesas europeias, aparece uma princesa nativa americana, uma árabe e uma oriental:

${ }^{12} \mathrm{O}$ filme é a versão adaptada da Disney do contos de fadas “A Pequena Sereia”, escrito pelo dinamarquês Hans Christian Andersen. 
[...] O discurso multiculturalista que cresceu na década de 90 pelas demandas globalizantes fez com que os estúdios da Disney criassem heroínas de diferentes etnias, fomentando a venda dos seus produtos. Nessa época, foram criadas Pocahontas, que representa uma americana nativa, e Jasmine, uma princesa árabe que tem suas características étnicas atenuadas para não se distanciar do padrão de beleza hegemônico [...] (CECHIN, 2014, p. 142).

Além das transformações nas características físicas, as princesas também se tornaram mais rebeldes, pois passaram a enfrentarem regras, lutarem por seus sonhos e/ou ideais e mudarem seus próprios destinos (AGUIAR; BARROS, 2015). Essa mudança no estereótipo das princesas Disney pode ser entendida como reflexo ao movimento feminista e discussões adjacentes, que foram se fortalecendo ao longo do século XX (MAIA et al., 2020). Assim, consideramos que a sociedade passa por mudanças ao longo da história:

[...] sob a influência deste novo período, com aspirações femininas inovadoras, a Disney criou princesas atreladas à realidade vigente independentes, questionadoras, determinadas e obstinadas - velando pela diferença étnica, que atendia aos padrões de globalização que despontavam no período [...] (AGUIAR; BARROS, 2015, p. 8).

Imergindo nos novos padrões, o filme A Bela e a Fera ${ }^{13}$ (1991) é o primeiro filme em que ocorre a inversão nos padrões de beleza e de papeis salvacionistas. No filme, a protagonista Bela tem por passatempo preferido o hábito da leitura. Porém, na história há o anti-herói e macho alfa Gastão, que insiste em casar-se com Bela; Gastão é a personificação do homem machista, egoísta e androcêntrico, que desvaloriza as virtudes de Bela "não é direito uma mulher ler... Logo, começa a ter ideias, a pensar!" (A Bela e a Fera, 1991). Em controvérsia, para Bela o sabichão Gastão é um 'homem primitivo' e recusa-se casar com ele; a jovem motivada por seu espírito altruísta e a fim de salvar a vida de seu velho pai, Bela decide morar em um castelo, em que vive uma fera com aparência monstruosa. A história segue com Bela empenhada em ensinar virtudes ao monstro e transformá-lo, porém, acaba apaixonando-se por ele, passando a equivocada "[...] ideia de que as mudanças do parceiro estão relacionadas a uma salvação por meio do amor [...]" (MONTEIRO; ZANELLO, 2014, p. 39). Ainda, observa-se que Bela tanto assume a posição de cuidadora (do pai e de Fera), quanto remete à subjetivação de

${ }^{13}$ O filme é a versão adaptada da Disney do contos de fadas “A Bela e a Fera”, escrito pela francesa Madame Jeanne-Marie LePrince de Beaumont. 
mulheres que estão dispostas a fazer tudo por outrem. A história finda quando Bela com seu amor verdadeiro salva Fera do feitiço, e em virtude disso, ressurge o príncipe encantado. Ou seja, Bela ter valorizado as virtudes, e não a beleza física de Gastão, encontrou o príncipe de suas histórias preferidas. Deste modo, a Disney justifica o discurso da beleza interna:

[...] para a Disney, o mal é representado pela feiura, enquanto os heróis demonstram formosura e beleza. Segundo esses preceitos, os sujeitos que apresentam corpos disformes, fora dos padrões estabelecidos, devem compensar esse desajuste com certa candura, ingenuidade, bondade e "beleza interna" para serem diferenciados dos vilões. Luz e trevas são representadas como a antítese entre bem e mal, própria dos preceitos medievais [...] (CECHIN, 2014, p. 140).

Nesse sentido, beleza, riqueza e casamento são símbolos de poder e status nos filmes animados da Disney. Em Aladdin ${ }^{14}$ (1992), aparecem novidades: Jasmine é a primeira princesa árabe da franquia, se contrapõe ao casamento arranjado entre famílias nobres e se apaixona por um personagem com posição social menos privilegiada (AGUIAR; BARROS, 2015). Ela consegue convencer seu pai (o sultão), que não é um prêmio, e consegue mudar a lei do casamento do seu país, permitindo-lhe casar-se com quem escolher; no caso, a escolha de Jasmine foi casar-se com o pobre e órfão Aladdin. Assim, cabe ainda ressaltar que a princesa Jasmine é uma representação das mulheres questionaram o casamento arranjado e reivindicaram o direito de escolha no casamento:

[...] Estas princesas também são instadas ou mesmo empurradas para casamentos que rejeitam, e assim a ideia de amor e casamentos nesses filmes recentes é complicada e envolvida em uma questão maior de escolha e liberdade diante das culturas tradicionais constrangedoras. Em vez de cantar sobre "algum dia" quando um "príncipe virá" (como Branca de Neve faz), essas princesas cantam canções em que seus desejos de se libertar de suas culturas restritivas são deixados claros. Jasmine canta "um mundo completamente novo", onde as pessoas não vão dizer-lhe o que fazer; Pocahontas repreende John Smith e o público sobre suas percepções equivocadas da selvageria; Mulan canta que ela "não está destinada a desempenhar esta função" (de uma noiva tradicional e uma boa filha); e Tiana (em "Quase Lá") rejeita "esta cidade velha" e seu povo, que "sempre tomam o caminho mais fácil" [...] (MITCHELL-SMITH, 2012, p. 217).

${ }^{14} \mathrm{O}$ filme é a versão adaptada da Disney do conto árabe "Mil e uma noites", que é uma compilação de diferentes autores-narradores. O conto árabe de Aladin foi acrescentado pelo francês Antoine Galland, na oportunidade em que o livro foi traduzido para o Ocidente. Disponível em: https://super.abril.com.br/mundo-estranho/quem-escreveu-as-mil-e-uma-noites/. Acesso em: 09 set. 2020. 
Pocahontas é a primeira princesa nativo-americana introduzida na franquia, e portanto, simboliza a beleza da mulher das comunidades nativas. No filme Pocahontas ${ }^{15}$ (1995), a princesa rejeita casar-se com o guerreiro prometido da aldeia, contrapondo-se às leis de sua tribo. Ainda, na adaptação fílmica, há um conflito entre os colonizadores e os nativos, no qual Pocahontas salva a vida do seu amado, o colonizador John Smith, e convence os colonizadores ingleses a respeitarem seu povo. Dessa forma, o filme animado Pocahontas (1995) é, na verdade, uma tentativa de ludibriar as relações de poder apresentada: a exploratória colonização europeia e a dominação perpetrada homemmulher (TELES; MELO, 2003). No final do filme, Pocahontas é convidada ir para a Europa, juntamente com seu amado, mas a nativa opta por permanecer em sua terra e assumir a responsabilidade que lhe própria com seu povo. Desse modo, no enredo fílmico, a mocinha salva o mocinho e torna-se o elo entre colonizadores e colonizados com vistas a combater a ideia preconceituosa de selvageria dos povos tribais, a qual recorrentemente é reproduzida nos filmes americanos. Acerca disso, Louro salienta que:

[...] Nos filmes hollywoodianos, articulavam-se de um modo especial às marcações de raça/etnia, gênero e sexualidade: mulheres negras e latinas eram, usualmente, representadas como sensuais; mulheres orientais pareciam sempre dóceis e submissas, e as brancas deveriam ser castas ou recatadas, capazes de deter as investidas dos homens (...) os mocinhos eram fortes, corajosos, decentes por vezes solitários e silenciosos. Invariavelmente brancos, lutavam contra índios, mexicanos e degenerados de todo tipo. Em tais filmes, dirigidos prioritariamente ao público masculino, o final feliz não supunha, necessariamente, o encontro do par amoroso. Ao encerrar da trama, muitas vezes se via o herói cavalgando sozinho, deixando a cidade e até a mocinha (que antes salvara) e se lançando para o horizonte ilimitado à sua frente [...] (LOURO, 2008, p. 83-84).

Outro importante filme é Mulan ${ }^{16}$ (1998), que representa a questão de igualdade de condições entre os gêneros. Mulan é a princesa representativa dos orientais. A história evidencia, como local de fala, mulheres silenciadas e invisibilizadas, que se limitam aos

15 O filme é a versão adaptada da Disney da personagem histórica de apelido "Pocahontas", cujo nome era Matoaka, do povo nativo-americano da nação Powhatan. Disponível em: https://tudorbrasil.com/2015/12/20/a-verdadeira-e-tragica-historia-de-

pocahontas/\#: :text=Pocahontas\%20nasceu\%20em\%20meados\%20de,mimada\%E2\%80\%9D\%20ou\%20 $\%$ E2\%80\%9Cimpertinente\%E2\%80\%9D. Acesso em: 04 set. 2020.

${ }^{16} \mathrm{O}$ filme é a versão adaptada da Disney da personagem histórica-lendária "Hua Mulan" — cujo nome significa "flor" (Huā) e "magnólia" (Mùlán) — baseada no imaginário chinês, da música A Balada de Mulan (The Ballad of Mulan). Disponível em: https://revistagalileu.globo.com/Sociedade/Historia/noticia/2020/09/mulan-conheca-verdadeira-e-tragicalenda-da-guerreira-chinesa.html. Acesso em: 04 set. 2020. 
trabalhos domésticos, aos cuidados maternais e honrar a família encontrando um bom casamento. Nesta adaptação fílmica a jovem Mulan foi reprovada no teste de noiva, no qual as características requeridas era demostrar ser uma moça "calma, reservada, graciosa, educada, refinada, equilibrada, pontual..." (Mulan, 1998). Apesar de questionadora, a princesa oriental foi educada a silenciar-se perante homens. Porém, ao notar que seu velho pai havia sido convocado como guerreiro na batalha de guerra, a jovem transgride as normas sociais impostas, disfarça-se de homem e enfrenta a batalha do lugar de seu pai - mesmo ciente que corria risco de morte. A guerreira demonstra coragem, honra, observação perspicaz e muita criatividade para vencer os inimigos, destacando-se perante os soldados-homens. O filme finaliza com o reconhecimento do imperador do 'fardo de Mulan', visto que ela salvou a vida de todos/as; ou seja, foi preciso que Mulan 'salvasse a China' para ser reconhecida como uma mulher honrosa perante a sociedade; assim o filme aproxima-se da crítica feminista decolonial que problematiza o mecanismo de subjetivação de mulheres, como aquelas que tudo suportam. Ademais, é possível perceber que

[...] a mulher tem tanta capacidade, coragem e força quanto o homem, podendo perfeitamente assumir qualquer papel que, por uma ideologia machista somente poderia ser desempenhado por este. A crítica à repressão e diminuição da figura feminina é contundente, sendo Mulan a única princesa deste período que se opõe ao modelo vigente para proteger e honrar seu pai e não por amor a um príncipe [...] (AGUIAR; BARROS, 2015, p. 10).

Dando continuidade na cronologia dos filmes elencados, adentramos à crítica feminista referente à normatividade branca das princesas Disney. Assim surge Tiana, a primeira princesa negra da Disney, referente ao filme A Princesa e o Sapo ${ }^{17}$ (2009), o qual dá início à fase das destemidas princesas contemporâneas (AGUIAR; BARROS, 2015). Além da inovadora questão de raça, o filme também aborda a questão de classe: Tiana é uma jovem de classe baixa, que trabalha muito para realizar o sonho de abrir o próprio restaurante. Ocasionalmente, encontrou um sapo falante, que na verdade era o príncipe Naveen; disposta a ajudá-lo a retornar a sua forma humana, Tiana beija o sapo, mas na verdade, acaba transformando-se em uma rã. Então, como verdes anfíbios, os dois passam a maior parte do filme buscando desfazer o encantamento, entretanto

${ }^{17}$ O filme é a versão adaptada da Disney do contos de fadas "O Príncipe Sapo", escrito pelos alemães de Jacob e Wilhelm Grimm. 
[...] Naveen foge à regra da representação de príncipes dos filmes da Disney. Nenhum outro príncipe fora retratado desta maneira até este desenho animado. Além de ser negro e bonvivant, a personagem não é o "solucionador de problemas", disposto a salvar a mocinha de todas as formas possíveis. Ao contrário, é retratado como "causador de problemas", um "anti-herói", um "boa vida" charlatão (...) Consideramos que no filme A princesa e o sapo, ao contrário dos príncipes brancos, os negros não são confiáveis [...] (BALISCEI; ANDRADE, 2015. p. 9).

Ainda, no final da trama, depois de superarem desafios e muito aprenderem juntos, os dois apaixonam-se. Após um beijo verdadeiramente apaixonado entre o sapo Naveen e a rã Tiana, os dois transformam-se novamente em humanos. Ao final, Tiana e Naveen se casam e juntos realizam o sonho de Tiana de abrir seu próprio restaurante. O filme representa uma tentativa frustrada da Disney de produzir um filme que se aproximasse dos discursos igualitários e interseccionais de classe-gênero-raça, porém:

[...] Ao final do filme, Tiana e Naveen encontram o seu "felizes para sempre" no trabalho com o restaurante, servindo as pessoas brancas - $\mathrm{o}$ que parece confirmar e reforçar os estereótipos de servidão para negros e negras e de deleite e consumo para brancos e brancas. Talvez a narração fora organizada como se a redenção de suas mazelas de caráter pudesse ser efetivada através do trabalho manual e de servidão no restaurante. Ou talvez a história reforce os limites e possibilidades de "finais felizes" que um casal negro pode conquistar. Cinderela, Ariel, Bela, Aurora, Branca de Neve tiveram "finais felizes" semelhantes a esse? [...] (BALISCEI; ANDRADE, 2015. p. 15)

Seguindo a experiência de "A Princesa e o Sapo" (2009), no filme Enrolados ${ }^{18}$ (2010) também aparecem contrastes de gênero, no qual o mocinho Flynn Rider é um ladrão, interesseiro e covarde, mas que acaba aprendendo lições éticas com Rapunzel, a princesa perdida dos cabelos compridos, dourados, brilhantes e encantados. Na versão Disney, Rapunzel é uma jovem que busca independência e autonomia como representatividade à libertação dos tradicionais padrões comportamentais; seu maior sonho não é encontrar um príncipe encantado, mas sim, sair da torre e ver de perto as 'luzes flutuantes'. Através de uma troca de favores, Flynn ajuda Rapunzel a sair da torre e realizar seu sonho, mas é a princesa quem salva a vida do anti-herói. Ao final da história, de volta ao reino, após longos anos de insistência, Rapunzel resolve aceitar os inúmeros

${ }^{18}$ O filme é a versão adaptada da Disney do contos de fadas "Rapunzel", escrito pelos alemães de Jacob e Wilhelm Grimm. 
pedidos de casamento de Flynn e contraria a tradição dos amores à primeira vista das princesas clássicas

[...] O que se nota, todavia, é que, se por anos, a Disney manteve esse padrão clássico dos contos de fadas, empregando essa roupagem até mesmo em histórias que originalmente não tinham qualquer relação com o gênero, como Pocahontas (1995) e Mulan (1998), nas últimas adaptações elas têm sido apresentadas de forma diferente. $\mathrm{O}$ modelo princesa em perigo ainda persiste, mas ela já não espera para ser salva e, muitas vezes, é ela a heroína da história. Já as relações amorosas românticas, antes a protagonista da trama, agora têm sido deixadas para segundo plano em favor de outras relações. Além disso, esses relacionamentos amorosos entre o príncipe e a princesa têm se constituído sob um novo padrão que envolve maior participação dele na história e praticamente elimina o "amor à primeira vista" e o "felizes para sempre” [...] (KESTERING, 2017, p. 4).

Na sequência das princesas Disney, encontramos os dois últimos filmes: Valente (2012) e Moana (2016). Neles, há a busca pela desconstrução da diferença entre os gêneros e a ressignificação identitária da figura feminina: destemida, determinada, audaciosa e sem necessidade de atrelar o final feliz da história com um casamento heteronormativo. Deste modo, os filmes das princesas Disney são representações sociais dos anseios das mulheres em suas épocas (DE LAURETIS, 1994), de modo que

[...] apesar das conquistas já alcançadas pela mulher, é inegável que a igualdade de direito ainda é uma realidade relativamente distante, pois [...] o ideal igualitário propugnado pelo movimento feminista assumiu a vertente, na prática, de cumulação de funções, e não igualdade propriamente dita. Isto porque ainda existe diferença salarial para homem e mulher que ocupam o mesmo cargo, além do papel feminino ser mantido, com certa dose de ideologia machista, no que toca aos cuidados da casa e dos filhos. Ainda assim, não se pode negar a autonomia, liberdade e independência financeira e social alcançadas pela figura feminina, tendência esta que foi seguida pelas últimas produções da Disney, que refletem essas mudanças, criando novas representações e identidades, inclusive desvinculadas da necessidade da figura masculina para encontrar a felicidade [...] (AGUIAR; BARROS, 2015, p. 10-11).

Assim, o filme Valente ${ }^{19}$ (2012), é protagonizado por Merida, uma jovem, de cabelos ruivos, compridos e de cachos rebeldes, além de muito desafiadora, aventureira, habilidosa com cavalos e exímia arqueira. Merida é uma princesa inconformada com as

${ }^{19} \mathrm{O}$ filme é protagonizado por uma personagem inédita, cuja origem não remete contos de fadas, contos históricos ou folclóricos. 
normatizações sociais de gênero impostas por sua mãe, a rainha Elionor, que é uma mulher altiva, perseverante e incansável quanto à tarefa de ensinar à filha comportamentos tipicamente femininos e dignos da realeza "uma princesa nunca levanta a voz , [...] não ri assim, [...] não enche muito a boca, [...] deve ter compaixão, ser paciente, cautelosa, [...] deve ser asseada em tudo, [...] uma princesa busca perfeição [...] é uma dama" (Valente, 2012). Merida, por sua vez, é rebelde; luta pelas rédeas do seu próprio destino, contra a obrigatoriedade de aceitar um casamento arranjado e desafia a família e a sociedade com o discurso icônico "pela minha própria mão, eu vou lutar!" (Valente, 2012). Neste ensejo, Merida não aceita as tradições (sociais e/ou familiares) e consegue libertar-se do casamento imposto. Além disso, Merida, é a primeira princesa que não tem um relacionamento amoroso ao longo do filme. Ainda, contrapondo ao típico padrão dos filmes hollywoodianos é a heroína quem encerra a produção cinematográfica, cavalgando sozinha e lançando-se ao horizonte (LOURO, 2008, consagrando-se como uma antiprincesa feminista, que luta por seu destino e por suas escolhas.

E por fim, Moana - um mar de aventuras ${ }^{20}$ (2016) é o filme mais recente das dentre as princesas da franquia Disney. Moana, uma jovem indígena da Polinésia, de cabelos ondulados, compridos e volumosos. No filme há o conflito entre o patriarcado e as ambições femininas - visto que o pais a reprime navegar em alto mar, além dos recifes. Esse conflito familiar é compreendido pelo fato de que Moana quer ir além das normativas de gênero e das tradições do povoado, quer ser livre e aventureira. No discurso musicado, Moana questiona seus desejos e personalidade "tento obedecer, não olhar pra trás... Sigo meu dever, não questiono mais... Mas pra onde vou, quando vejo, estou onde eu sempre quis [...] Por que sou assim?” (Moana, 2016). Porém, após a morte da matriarca da aldeia (a avó), a jovem indígena decide aceitar a missão dos deuses e embarcar em uma viagem pelo oceano a fim de mudar o destino de seu povo. No decorrer da missão, ela conta com a ajuda do semideus Maui, um típico sabichão machista, que questiona papeis de gênero "Você não devia estar na aldeia cuidando dos bebês?" (Moana, 2016), e até mesmo brinca com o estereótipo das princesas Disney "Se está de vestido e tem um bichinho de estimação... Você é uma princesa!” (Moana, 2016). Entretanto, ao longo do filme, a antiprincesa tribal vai se empoderando da importância de seu papel e lugar "Não sou princesa, eu sou a filha do chefe [...] Eu sou Moana de Motunui. A bordo do meu

${ }^{20} \mathrm{O}$ filme é protagonizado por uma personagem inédita, cuja origem não remete contos de fadas, contos históricos ou folclóricos. Entretanto, o semideus Maui é baseado em um dos mais importantes personagens da mitologia dos povos da Polinésia. 
barco, navegarei por todo o mar e restaurarei o coração de Te Fiti” (MOANA, 2016). Desse modo, Moana consegue concluir a missão de libertar a ilha e seu povoado da maldição. Ao final do filme é coroada como chefe da tribo, sendo a segunda antiprincesa que não apresenta relacionamento amoroso ao longo do filme:

[...] Nessa animação, não há príncipe encantado ou princesas em perigo, e nenhuma menção ao amor verdadeiro é realizada. A ligação familiar especial não é exclusiva do pai, a avó é quem tem maior influência sobre a heroína. Em suma, se trata de uma declaração de que o amor romântico não será mais um constituinte importante que restringe a aventura da protagonista. Ao que parece, as novas histórias de princesa da Disney finalmente aderiram às críticas e caminham para uma representação mais igualitária dos papéis sociais de cada gênero [...] (KESTERING, 2017, p. 143).

Diante do exposto, é possível afirmar que nos doze filmes de animação, correspondentes às princesas Disney, são observadas questões de gênero nos discursos analisados.

\section{Filmes enquanto formação midiática e educacional}

Assim como, “[...] as crianças assistem a esses filmes inúmeras vezes - seja em casa, no cinema ou na própria escola - decorando as músicas, os gestos, os diálogos [...]" (SABAT, 2001, p. 1) é fundamental a análise e compreensão dos discursos eivados nos filmes de animação. A partir das análises realizadas, foi possível perceber que a princesa dos filmes da Disney, enquanto personagem protagonista, histórico-cultural e simbólica dos femininos, vem incorporando um perfil mais empoderado e ativo socialmente. Aquele estereótipo feminino apresentado no primeiro filme animado da Disney, Branca de Neve e os Sete Anões (1937), e seguido em Cinderela (1950) e A Bela Adormecida (1959), no qual a princesa era submissa, passiva e se sentia satisfeita em realizar os trabalhos domésticos, enquanto que o príncipe era o símbolo salvacionista de um completo final feliz (BEAUVOIR, 2009), paulatinamente, vai dando espaço para uma princesa mais corajosa, independente, empoderada e que luta por outros ideais, sonhos e propósitos de vida. Essa mudança é perceptível nos estereótipos femininos apresentados nos filmes mais remanescentes: Valente (2012) e Moana (2016).

Destarte, quando pensamos em histórias de princesas, automaticamente, associamos ao final feliz representado pelo amor romântico, pelo beijo apaixonado ou 
casamentos heteronormativos, como acontece nos filmes de oito princesas: Branca de Neve, Cinderela, Aurora, Ariel, Bela, Jasmine, Tiana e Rapunzel. Entretanto, diante da crítica feminista de que a figura das princesas reforçava ideias patriarcais na sociedade, a Disney movida pelo interesse mercadológico, capitalista promoveu a atualização nos roteiros dessas histórias e a quebra do tabu normativo de que a mulher deve ser delicada e esperar pacienciosamente pelo príncipe encantado. Deste modo, com as transformações no perfil da figura feminina surgiram as princesas empoderadas (ou antiprincesas), como é o caso de Pocahontas, que escolheu ficar com seu povo nativo ao invés de acompanhar o colono branco em retorno à Europa. Já, com a guerreira Mulan houve o indício de que capitão Li Shang seria seu futuro pretendente, e portanto, mesmo com todas as transgressões realizadas pela heroína ao longo da história, ao final do filme, é reproduzida a concepção de que para a completude feminina é indispensável estar ao lado de um homem. Em contrapartida, Merida, foi única princesa que rejeitou enfaticamente a ideia do casamento. Ademais, a efetiva inovação aparece com Moana, pois no filme esse tema definitivamente não foi o foco do enredo, mas sim as conquistas, os desafios, as vitórias e as aventuras da heroína.

Outra consideração relevante "[...] é a importância simbólica dos cabelos [...]" (PERROT, 2008, p. 61), pois “[...] os cabelos são a mulher, a carne, a feminilidade, a tentação, a sedução, o pecado [...]” (PERROT, 2008, p. 55). Nos filmes analisados, é nitidamente observada a relação entre os cabelos das protagonistas como marca de transgressão das personagens, pois quanto mais rebelde a princesa, mais apresenta cabelos cacheados, volumosos e indomáveis (como é o caso de Valente e Moana, em contraposição com os cabelos lisos, sedosos e impecáveis da maioria das princesas). No caso de Mulan, a jovem demonstra um ato de coragem e ruptura ao cortar suas madeixas, ou seja, é uma ação simbólica de rompimento com as questões de sua feminilidade, excluindo-se do papel de ser feminina. Ainda a garota pobre, negra e dos cabelos crespos Tiana, foi a única das princesas analisadas que não aparece com seus cabelos soltos ao vento, demonstrando talvez ser uma princesa oprimida pelas múltiplas desigualdades vividas (gênero, classe e raça). Ainda, tomando como referência bell hooks ${ }^{21}$, talvez a princesa Tiana não tenha soltado suas madeixas por ser a única princesa com os cabelos

\footnotetext{
${ }^{21}$ Para hooks o cabelo está vinculado historicamente a um sistema de dominação racial, especialmente para as mulheres negras. In: Revista Gazeta de Cuba - Unión de escritores y Artista de Cuba, janeiro-fevereiro de 2005. Tradução do espanhol: Lia Maria dos Santos. Retirado do blog coletivomarias.blogspot.com/.../alisando-o-nossocabelo.html. Acesso em: 20 out. 2020.
} 
crespos (e não alisados), ou seja, para ser aceita no padrão da franquia Disney Princesa, tentaram aproximar a princesa negra aos padrões normativos de branquitude e socialmente aceitos de beleza, e assim, manter escondido os cabelos crespos possivelmente tenha sido a proposta e/ou solução para garantir as vendas comerciais da franquia.

Os filmes analisados buscam contemplar a representatividade feminina, ou seja, a Disney em busca de expansão dos territórios mercadológicos busca abarcar as diferentes nacionalidades, etnias e concepções do feminino. Desta forma, os filmes animados da Disney vêm lentamente desconstruindo estereótipos de gênero e buscando arquétipos femininos mais próximos da igualdade de gêneros, representatividade e interseccionalidades, revelando que há outros estilos de ser mulher e que os papeis de gênero são construções histórico-sociais (SCOTT, 1995), ou seja, a mulher é capaz de fazer o que quiser! Diante do exposto, sem dúvidas, os filmes animados constituem uma fonte documental de pesquisa, assim como, um recurso midiático e pedagógico para o público infanto-juvenil, pois a partir desses artefatos culturais é possível estabelecer complexas discussões de gênero, tais como sistema patriarcal, questões de igualdade/desigualdade de gênero, inversão de papeis, interseccionalidade de classe, raça e gênero, entre outras:

[...] somente com a problematização e a reflexão sobre essas imagens é possível ajudar as crianças a desenvolverem um senso crítico sobre os preconceitos de corpo, raça, etnia, geração e comportamento. Encontrase aí a importância da educação para que se possa pensar modos de produzir uma maior conscientização ética [...] (CECHIN, 2014, p. 145).

Nesta perspectiva, a partir de rodas de conversas formais e/ou informais, bate papos e reflexões dos filmes animados analisados é possível ensinar o público infanto-juvenil, a lidar melhor com suas emoções, lutar por seus sonhos e confiar que mudanças dependem de si mesmo. É incentivar e fazer acreditar que todo indivíduo é livre para fazer suas escolhas e ser feliz do jeito que quiser. É fortalecer a ideia do empoderamento! Essa é uma das formas de resgatar a autoestima feminina e educar as garotas e/ou futuras mulheres a se defenderem diante de situações misóginas, de desigualdade de gênero, de relacionamentos abusivos, etc. É compreender que a mulher é historicamente reprimida, passiva e submissa perante homens machistas e reprodutores do patriarcalismo. É educar pela alteridade e igualdade: homem e mulher, ocidental e oriental, pobre e rico, branco, 
negro e indígena, ou seja, todos são humanos e devem ter acesso aos mesmos direitos, lugares e papeis.

\section{Considerações finais}

Os filmes representam uma tecnologia de gênero. Neste sentido são fontes de pesquisa histórica, assim como, materiais pedagógicos para o ensino da própria História. Porém, esse recurso tecnológico precisa ser analisado com criticidade e consciência de que não apresentam discursos neutros - inclusive na categoria animação. Todos os filmes são repletos de estereótipos, discursos e imaginários coletivos que são reproduzidos e reforçados em dimensões globais. Portanto, o cinema é uma tecnologia hegemônica de construção e representatividade de gênero, o que foi demostrado ao longo dessa análise histórica e cronológica dos filmes das princesas Disney.

Ainda é possível afirmar que o movimento feminista trouxe pautas, questionamentos e discussões de gênero que causaram impactos e transformações no estereótipo das princesas Disney. O gênero, enquanto categoria histórica é parte constitutiva das relações sociais. Desse modo, não são as diferenças biológicas que vão demarcar papéis, mas sim, independente de classe, raça e/ou gênero cada indivíduo deve ser valorizado por suas próprias características e jeitos de ser. Produzir ou reproduzir discursos que reforçam papéis de gêneros e relações de poder entre os sexos já é algo digno de enfrentamento. A luta social e feminista é pelo rompimento com as desigualdades de classe, raça e/ou gênero, bem como, a construção de uma sociedade mais justa, plural e equânime para todos/as.

É claro que há muito o que se avançar nos roteiros dos filmes animados de princesas, pois nos discursos analisados o padrão normativo e corporal valorizado como sinônimo de poderio, status e beleza, são os corpos predominantemente jovens, heterossexuais, brancos e magros. A partir de Foucault também se observa que o cinema é a educação dos corpos nos padrões normativos e nos jogos simbólicos de poder contemporâneos do sistema capitalista. Porém, sabendo que questões de gênero estão implícitas no cinema e em outros artefatos da cultura humana, não cabe à sociedade tentativas de velar essa discussão. O caminho é desmistificar paradigmas enraizados e incentivar que as instituições educacionais formais e/ou informais (como a família, a escola e as produtoras cinematográficas - enquanto formadoras de opinião e conhecimento) não reproduzam ideologias machistas, heteronormativas, burguesas e 
dominantes, mas sim façam juz ao seu papel social de formadores/as de cidadãos autônomos e livres de preconceitos ou crenças limitantes.

\section{Referências}

AGUIAR, Eveline Lima de Castro; BARROS, Marina Kataoka Barros. A Representação Feminina nos Contos de Fadas das Animações de Walt Disney: a Ressignificação do Papel Social da Mulher. In: Intercom - Sociedade Brasileira de Estudos Interdisciplinares da Comunicação / XVII Congresso de Ciências da Comunicação na Região Nordeste. Natal, 2015. 2 p. 1-15. Disponível em: https://www.portalintercom.org.br/anais/nordeste2015/resumos/R47-1959-1.pdf. Acesso em: 06 maio 2020.

BEAUVOIR, Simone de. O Segundo sexo. Tradução de Sérgio Milliet. 2 ed. Rio de Janeiro: Nova Fronteira, 2009. 807 p.

BUTLER, J. Problemas de gênero: feminismo e subversão da identidade. Rio de Janeiro: Civilização Brasileira, 2003. 235 p.

CARVALHO, J. M. A Formação das almas: o imaginário da república no Brasil. São Paulo: Companhia das Letras, 1987. 174 p.

CECHIN, Michelle Brugnera Cruz. O que se aprende com as princesas da DISNEY?. Zero a Seis, Florianópolis, v. 16, n. 29, p. 131 - 147, jan. 2014. Disponível em: https://periodicos.ufsc.br/index.php/zeroseis/article/view/19804512.2014n29p131/26131. Acesso em: 09 mar 2020.

COLLINS, Patricia Hill. Intersectionality's definitional dilemas. Annual Review of Sociology, Palo Alto, n. 41, p. 1-20, 2015. Disponível em: https://www.annualreviews.org/doi/pdf/10.1146/annurev-soc-073014-112142. Acesso em 14 abr. 2020.

DE LAURETIS, Tereza. A Tecnologia do Gênero. In: HOLLANDA, Heloisa Buarque de (org.), Tendências e Impasses: o feminismo como crítica da cultura, Rio de Janeiro: Rocco, 1994. p. 206-242

FERRO, Marc. Cinema e História. Rio de Janeiro: Paz e Terra, 1992. 143 p.

FOUCAULT, Michel. A arqueologia do saber. 8. Ed. Rio de Janeiro: Forense Universitária, 1969. 243 p.

FOUCAULT, Michel. A ordem do discurso. São Paulo: Loyola, 1996. 79 p.

FOUCAULT, Michel. História da sexualidade 1: A vontade de saber. Lisboa: Relógio D’Água Editores, 1994. 153 p.

GARCIA, Dantielli Assumpção; SOUSA, Lucília Maria Abrahão. A sororidade no 
ciberespaço: laços feministas em militância. Estudos linguísticos, São Paulo, São Paulo, 44 (3): p. 991-1008, set.-dez. 2015. Disponível em: https://revistas.gel.org.br/estudoslinguisticos/article/view/1032/613. Acesso em: 15 set. 2020.

GIROUX, Henry. A dysneização da cultura infantil. In: SILVA, Tomaz Tadeu da; MOREIRA, Antônio Flávio (orgs.). Territórios contestados: o currículo e os novos mapas políticos e culturais. Petrópolis: Vozes, 1995. p, 41-81.

HOOKS, Bell. Feminist theory: from margin to center. Boston: South End Press, 1984.

KESTERING, Virginia Therezinha. Da princesa em perigo ao príncipe descartado: o amor romântico nos filmes de princesa da Disney. 2017. 162 f. Dissertação (Mestrado em Sociologia) - Universidade Federal de Minas Gerais, Belo Horizonte, 2017.

LE GOFF, Jacques. Documento/Monumento. In: LE GOFF, Jacques. História e memória. 6. ed. Campinas; São Paulo: Editora da Unicamp, 1990. p. 462-478.

LOURO, Guacira. Cinema \& Sexualidade. Educação \& Realidade. Porto Alegre, v. 33, n. 1, p. 81-98, jan./jul. 2008. Disponível em:

https://seer.ufrgs.br/educacaoerealidade/article/view/6688/4001. Acesso em: 19 maio 2020.

LUGONES, María. Hacia un feminismo descolonial. La manzana de la discórdia, v.6, n.2, p.105-119, 2011.

MAIA, Ana Claudia Bortolozzi. et al. Padrões de beleza, feminilidade e conjugalidade em princesas da Disney: uma análise de contingências. Diversidade e Educação, [S.1.], p. 123 - 142, mar. 2020. ISSN 2358-8853. Disponível em:

<https://periodicos.furg.br/divedu/article/view/9812/7255>. Acesso em: 26 out. 2020.

MEIRELLES, William R. O cinema como fonte para o estudo da História. História \& Ensino. Londrina, v.3, p.113-122, abr. 1997. Disponível em: https://silo.tips/download/ocinema-como-fonte-para-o. Acesso em 01 ago. 2020.

MENDES, Mariza B. T. Em busca dos contos perdidos. O significado das funções femininas nos contos de Perrault. São Paulo: Editora UNESP/Imprensa Oficial do Estado de São Paulo, 2000, 148 p. Disponível em:

http://www.dominiopublico.gov.br/download/texto/up000011.pdf. Acesso em: 14 set. 2020.

MITCHELL-SMITH, I. The united princesses of America: ethnic, diversity and cultural purity in Disney's medieval past. In: PUGH, T.; ARONSTEIN, S. The Disney Middle Ages: a fairy-tale and fantasy past. Nova York: Palgrave Macmillan, 2012. p. 209-224.

MONTEIRO, Clara; ZANELLO, Valeska. Tecnologias de gênero e dispositivo amoroso nos filmes de animação da Disney. Revista Feminismos, Salvador, v. 2, n. 3, p.36-44, set./dez. 2014. Disponível em:

<http://www.feminismos.neim.ufba.br/index.php/revista/article/view/159>. Acesso em: 20 out. 2020. 
NAPOLITANO, Marcos. A História depois do papel. In: PINSKY, Carla Bassanez (Org.). Fontes Históricas: $2^{\mathrm{a}}$ Ed, São Paulo: Contexto, 2008.

PERROT, Michelle. Minha história das mulheres. Tradução de Ângela M S. Correa. São Paulo: Contexto, 2008. 191 p.

PINSKY, Carla Bassanezi; PEDRO, Joana Maria (Orgs.). Apresentação. In: PINSKY, Carla Bassanezi; PEDRO, Joana Maria (Orgs.). Nova História das Mulheres no Brasil. São Paulo: Contexto, 2013. 268 p.

PINTO, Céli Regina. Elementos para uma análise de discurso político. Barbarói. $\mathrm{n}^{\circ} 24$ ano 2006/1. p. 78-109, 2005. Disponível em: https://online.unisc.br/seer/index.php/barbaroi/article/view/821. Acesso em 16 nov. 2020.

QUEIROZ, Maria Helena Tuanne. et al. Era uma vez: as princesas dos filmes da Disney do século XX e XXI e o "mito" da aparência e do corpo perfeito. In: Anais [...], Campina Grande: Realize Editora, 2016. p. 1-10. Disponível em:

https://editorarealize.com.br/artigo/visualizar/18469. Acesso em: 09 ago. 2020.

RABELO, Josiane Oliveira. A construção da subjetividade feminina: uma reflexão a partir dos contos de fadas dos irmãos Grimm. 2016. 105 p. Dissertação (Mestrado em Educação) - Universidade Tiradentes, Aracaju, 2016.

SABAT, Ruth. Infância e gênero: o que se aprende nos filmes infantis? In: $24^{a}$ reunião anual ANPEd. Caxambu, 2001. p. 1-11. Disponível em: http://24reuniao.anped.org.br/tp.htm\#gt7. Acesso em: 16 jul. 2020.

SCOTT, Joan. Gênero, uma categoria útil de análise histórica. Educação e realidade. Porto Alegre, v. 20, n.2, p. 71-99, jul./ dez., 1995. Disponível em: https://www.seer.ufrgs.br/educacaoerealidade/article/viewFile/71721/40667. Acesso em: 01 jun. 2020.

TARDIN, Elaine Borges; BARBOSA, Murilo Tebaldi; LEAL, Polliana da Costa Alberone. Mulher, trabalho e a conquista do espaço público: reflexões sobre a evolução feminina no Brasil. Revista Transformar, n. 7, p. 119-135, 2015. Disponível em: http://www.fsj.edu.br/transformar/index.php/transformar/article/view/34. Acesso em: 01 out. 2020.

TELES, M. A.; MELO, M. O que é violência contra a mulher (Coleção Primeiros Passos, 314). São Paulo: Brasiliense, 2003. 120 p.

XAVIER FILHA, Constantina. Sexualidade(s) e gênero(s) em artefatos culturais para a infância: práticas discursivas e construção de identidades. In: XAVIER FILHA, Constantina (Org.). Educação para a sexualidade, para a equidade de gênero e para a diversidade sexual. Campo Grande, MS: Ed. UFMS, 2009. p. 71-97.

\section{Filmografia}


A Bela Adormecida. Direção: Clyde Geronimi, Les Clark, Eric Larson e Wolfgang Reitherman. Produção: Walt Disney. Walt Disney Productions, 1959. 75 min, color.

A Bela e a Fera. Direção: Gary Trousdale e Kirk Wise. Produção: Don Hahn. Walt Disney Pictures, 1991. 84 min, color.

A Pequena Sereia. Direção: Ron Clements e John Musker. Produção: John Musker e Howard Ashman. Walt Disney Pictures, 1989. 82 min, color.

A Princesa e o Sapo. Direção: Ron Clements e John Musker. Produção: Peter Del Vecho e John Lasseter. Walt Disney Pictures, 2009. 97 min, color.

ALADDIN. Direção: Ron Clements e John Musker. Produção: Ron Clements e John Musker. Walt Disney Pictures, 1992. 90 min, color.

BRANCA de Neve e os Sete Anões. Direção: David Hand, William Cottrell, Wilfred Jackson, Larry Morey, Perce Pearce e Ben Sharpsteen. Produção: Walt Disney. Walt Disney Productions, 1937. 83 min, color.

CINDERELA. Direção: Clyde Geronimi, Hamilton Luske e Wilfred Jackson. Produção: Walt Disney. Walt Disney Productions, 1950. 74 min, color.

ENROLADOS. Direção: Nathan Greno e Byron Howard. Produção: Roy Conli, John Lasseter e Glen Keane. Walt Disney Pictures, 2010. 100 min, color.

MOANA - Um mar de aventuras. Direção: John Musker e Ron Clement. Produção: Osnat Shurer. Califórnia: Walt Disney Pictures, 2016. 103 min, color.

MULAN. Direção: Tony Bancroft e Barry Cook. Produção: Pam Coats. Walt Disney Pictures, 1998. 87 min, color.

POCAHONTAS. Direção: Mike Gabriel e Eric Goldberg. Produção: James Pentecost. Walt Disney Pictures, 1995. 81 min, color.

VALENTE. Direção: Mark Andrews e Brenda Chapman. Produção: Katherine Sarafian. Pixar Animation Studios, 2012. 93 min, cor. 